\title{
Novel anti-cancer role of naphthazarin in human gastric cancer cells
}

\author{
JIN-AH KIM ${ }^{1}$, EUN KYEONG LEE ${ }^{1}$, SEONG JOON PARK ${ }^{1,2}$, NAM DEUK KIM ${ }^{2}$, DONG-HOON HYUN ${ }^{3}$, \\ CHANG GEUN LEE ${ }^{1}$, JAE HO LEE ${ }^{1}$, KWANG MO YANG ${ }^{1,4}$, KYU HEO $^{1}$ and TAE GEN SON ${ }^{1}$ \\ ${ }^{1}$ Research Center, Dongnam Institute of Radiological and Medical Science, 40 Jwadong-gil, Jangan-eup, \\ Gijang-gun, Busan 619-953; ${ }^{2}$ Department of Pharmacy, Pusan National University, Geumjeong-gu, Busan 609-735; \\ ${ }^{3}$ Department of Life Science, Ewha Womans University, Seoul 120-750; ${ }^{4}$ Department of Radiation Oncology, \\ Korea Institute of Radiological and Medical Sciences, Seoul 139-706, Republic of Korea
}

Received July 5, 2011; Accepted August 17, 2011

DOI: $10.3892 /$ ijo.2011.1195

\begin{abstract}
Gastric cancer is one of the most common malignant tumors and the second cause of cancer-related deaths worldwide. Naphthoquinones such as juglone and plumbagin are compounds used extensively to overcome resistance to chemotherapeutic agents in cancers due to their cytotoxic role. This study is the first to investigate the anti-cancer effect of naphthazarin (Naph), one of the naphthaquinones, in human gastric cancer AGS cells. We showed that Naph exhibited effective preferential cell growth inhibition via G2/M phase arrest and apoptosis, which was associated with reduced levels of $\mathrm{Cdc} 2$ and $\mathrm{Cdc} 25 \mathrm{C}$ expression. Naph also increased cleaved caspase-3 and Poly ADR(adenosine diphosphate ribose) Polymerase expression, $\gamma$-H2AX expression (an indicator of DNA double strand breaks) and DNA fragmentation. We also found the generation of reactive oxygen species is a critical mediator in Naph-induced cell growth inhibition and apoptosis. The non-protein antioxidant, glutathione significantly abolished Naph-mediated inhibition of cell growth and apoptosis. Taken together, our findings showed that Naph not only inhibited cell growth, but also induced apoptosis of AGS cells, suggesting that Naph may be a potential candidate for cancer therapy against gastric cancers.
\end{abstract}

\section{Introduction}

Gastric cancer is one of the most common malignant tumors and the second cause of cancer-related deaths worldwide $(1,2)$. Chemotherapy for gastric cancer has been well developed, but a globally accepted standard chemotherapy and optical regimens have not yet been determined. Therefore, many studies have

Correspondence to: Dr Tae Gen Son, Research Center, Dongnam Institute of Radiological and Medical Science, 40 Jwadong-gil, Jangan-eup, Gijang-gun, Busan 619-953, Republic of Korea

E-mail: swanlakenz@yahoo.com

Key words: naphthazarin, anti-cancer, apoptosis, cell cycle arrest been undertaken to find and develop novel chemotherapeutic agents for gastric cancer.

Naphthoquinones such as juglone (JU) and plumbagin (PL) are found in plants as they are thought to be present as a defense mechanism due to their cytotoxicity. They are also used extensively in studies investigating oxidative stress. Substantial evidence has showed that naphthaquinones exert anti-cancer and anti-proliferative activities in animal models and in cell culture (3-6). JU induced apoptosis in human gastric cancer and melanoma cells via mitochondrial dysfunction $(3,4)$. JU and PL inhibited azoxymethane-induced intestinal carcinogenesis in rats (5). PL inhibits 12-O-tetradecanoylphorbol-13-acetate (TPA)-induced cell invasion and migration in A549 human lung cancer cells (6). PL induced apoptosis via ROS generation and depletion of intracellular GSH in human prostate cancer cells (7). PL has also been shown to induce cell cycle arrest in human lung and breast cancer cells (8-10).

Naphthazarin (Naph, 5,8-dihydroxy-1,4-naphthoquinone) is a naturally occurring organic compound. It was also found to induce intracellular oxidative stress in hepatocytes (11) as well as to cause apoptotic cell death $(12,13)$. Naph caused vascular dysfunction by impairment of endothelium-derived nitric oxide and increased superoxide anion generation (14). However, Naph, which has structural similarity with JU and PL, has not been studied as an anti-cancer agent. In this study, we analyzed the cytotoxicity of Naph as well as its ability to induce oxidative stress in AGS gastric cancer cells. We also investigated the anti-cancer effect of Naph and assessed its potential as a chemotherapeutic agent against gastric cancer.

\section{Materials and methods}

Cell culture and cell viability assay. AGS (human gastric cancer cells) cells were obtained from American Type Culture Collection (Manassas, VA) and maintained in DMEM medium (Hyclone, UT) in a humidified atmosphere of $37^{\circ} \mathrm{C}$ with $5 \% \mathrm{CO}_{2}$. DMEM supplemented with $10 \%$ heat-inactivated fetal bovine serum (FBS, Hyclone), 5\% antibiotic-antimycotic (Gibco, Carlsbad, $\mathrm{CA})$. The cell viability assay was seeded in a 6 -well plate $\left(3 \times 10^{5}\right.$ cells), and incubated at $37^{\circ} \mathrm{C}$ in a $5 \% \mathrm{CO}_{2}$ incubator for $24 \mathrm{~h}$. 
Cells were exposed to naphthazarin (Sigma-Aldrich, St. Louis, $\mathrm{MO}$ ) or plumbagin (Sigma-Aldrich) at concentrations of $0.5,1$, 5, 10 and $20 \mu \mathrm{M}$ for $24 \mathrm{~h}$. The compounds were dissolved at $10 \mathrm{mM}$ in dimetyl sulfoxide (DMSO) as a stock solution, and stored at $-80^{\circ} \mathrm{C}$. The stock solution was diluted with cell culture medium to the desired concentration prior to use. The maximal concentration of DMSO did not exceed $0.01 \%(\mathrm{v} / \mathrm{v})$ in the treatment range, where there was no influence on cell growth. Cell proliferation was measured by MTS assay (CellTiter $96 \mathrm{AQ}_{\text {ueous }}$ One Solution, Promega, Madison, WI). After $24 \mathrm{~h}$ treatment of $100 \mu 1$ of MTS solution was added to each well, and the plate was incubated at $37^{\circ} \mathrm{C}$ for $1 \mathrm{~h}$. The media containing MTS were transferred to a 96-well plate to read optical density at $490 \mathrm{~nm}$ in ELISA.

Western blot analysis. Total cells lysates were lysed in lysis buffer. Equal amount of protein extracts were denatured by boiling at $100^{\circ} \mathrm{C}$ for $5 \mathrm{~min}$ in sample buffer. Equal amount of the total proteins were subjected to $6-15 \%$ SDS-PAGE and transferred to PVDF. The membranes were incubated overnight at $4^{\circ} \mathrm{C}$ with the primary antibodies: Poly ADR(adenosine diphosphate ribose) Polymerase (PARP) (1:1000, Santa Cruz Biotechnology, Santa Cruz, CA), cyclin B1 (1:1000, Santa Cruz), Cdc2 (1:1000, Santa Cruz), Cdc25C (1:500, Santa Cruz), Bax (1:1000, Cell Signaling Technology, Danvers, MA), Bcl-xL (1:500, Cell Signaling Technology), caspase-3 (1:1000, Cell Signaling Technology), cleaved caspase-3 (1:500, Cell Signaling Technology), H2AX (1:1000, Abcam, London, UK). The following day the membranes were washed for $10 \mathrm{~min}$, 4 times each, and incubated with the secondary antibody: polyclonal anti-rabbit antibody (1:5000, Invitrogen, Carlsbad, CA) or monoclonal anti-mouse antibody (1:5000, Invitrogen). Antigen-antibody complexes were detected by the enhanced chemiluminescence detection system.

ROS generation. Cells were seeded at a density of $3 \times 10^{5}$ cells in a 6-well plate, and incubated at $37^{\circ} \mathrm{C}$ for $24 \mathrm{~h}$ in a $5 \% \mathrm{CO}_{2}$ incubator. The cells were treated with various concentration of Naph and the plate was incubated in incubator. After $30 \mathrm{~min}$, media were removed and the cells were washed 3 times with PBS and treated $25 \mu \mathrm{M}$ carboxy- $\mathrm{H}_{2}$ DCFDA containing serumfree media. The plate was washed gently 5 times with PBS and $1 \mu 1$ Hoechst 33342 was added. The stained cells were observed under Nikon Eclipse microscope (Nikon, Tokyo, Japan) with a FITC filter.

DNA damage assay. The DNA damage assay was carried out using the OxiSelect ${ }^{\mathrm{TM}}$ Comet Assay Kit (Cell Biolabs, San Diego, CA). Cells were seeded in 6-well plates and treated with various concentrations of Naph for $24 \mathrm{~h}$. The cells were harvest and then washed with PBS. The cell suspension $\left(1 \times 10^{5}\right)$ was mixed with low melting point agarose (1:10 ratio) and then $75 \mu \mathrm{l}$ of suspension was pipetted on the comet slide. The slides were incubated at $4^{\circ} \mathrm{C}$ for $30 \mathrm{~min}$ and the immersed in the lysis buffer for 30 min. Lysis buffer was aspirated from the slide and immersed in alkaline solution for $30 \mathrm{~min}$. Slides were placed in a horizontal electrophoresis chamber and electrophoresed with TAE buffer at $25 \mathrm{~V}$ for $20 \mathrm{~min}$. Slides were dried and stained with DNA dye. Comet tails were imaged using fluorescent microscope (Nikon, Tokyo, Japan).
Flow cytometric analysis. The cell cycle analysis was measured with propidium iodine (PI). Cells were trypsinized, washed with PBS, and fixed in $75 \%$ ethanol at $4^{\circ} \mathrm{C}$ overnight. Prior to analyses, cells were washed again with PBS, suspended in cold PI solution, and incubated at room temperature for $30 \mathrm{~min}$ in the dark. Flow cytometry analysis was performed on a FACScan (BD FACSAria ${ }^{\mathrm{TM}}$, BD Biosciences, San Jose, CA). The Annexin-V analysis was carried out using the PE Annexin V Apoptosis Detection kit (BD Biosciences). After the treatment, medium containing Naph was removed, cells were washed in cold PBS and then resuspended cells in $1 \mathrm{X}$ binding buffer at a concentration of $1 \times 10^{6}$ cells $/ \mathrm{ml}$. The cells were stained with PE annexin $\mathrm{V}$ and 7-amino-actinomycin (7-AAD) and incubated at room temperature for $30 \mathrm{~min}$. The cells were suspended before flow cytometry analysis.

Statistical analysis. Results are expressed as the mean \pm SD of three separate experiments and analyzed by Student's t-test. Means were considered significantly different at ${ }^{*} \mathrm{P}<0.05$, ${ }^{* *} \mathrm{P}<0.01$ or ${ }^{* * *} \mathrm{P}<0.001$

\section{Results}

Effect of naphthazarin on AGS gastric cancer cell viability and proliferation. AGS gastric cancer cells were treated with PL and Naph at the indicated concentration for $24 \mathrm{~h}$, and then a cell viability assay was performed using MTS assay. While no cytotoxicity in the cells was measured in the presence of PL at $1 \mu \mathrm{M}$, the other concentrations of 2.5 and $5 \mu \mathrm{M}$ showed 10 and $30 \%$ cytotoxicity, respectively. In contrast, Naph demonstrated cytotoxicity in cells at $1 \mu \mathrm{M}$ and strongly decreased cell viability by 40,55 and $90 \%$ at $1,2.5$ and $5 \mu \mathrm{M}$, respectively (Fig. 1A). These data showed that Naph was more cytotoxic than PL, indicating that Naph may have a better anti-cancer effect on AGS gastric cancer cells. Based on the dose-response study, it appeared that the cytotoxicity of Naph occurred primarily at a concentration between 0.5 and $1 \mu \mathrm{M}$. Thus, we selected $0.7 \mu \mathrm{M}$ of Naph for a proliferation study. When cells were treated with $0.7 \mu \mathrm{M}$ Naph for 24,48 and $72 \mathrm{~h}$, cell proliferation was significantly inhibited in time-dependent manner (Fig. 1B). In addition, we analyzed whether Naph induced morphological changes of AGS cells using light microscopy (Fig. 1C upper panel) and DAPI staining (Fig. 1C lower panel). AGS cells typically have a fibroblastic and flattened appearance, but cells treated with Naph were observed to have morphological changes indicative of apoptosis, including cell shrinkage. The number of DAPI-stained AGS cells was significantly reduced with Naph treatment.

Naphthazarin induces AGS cell death. Next, we investigated whether cells with abnormal DNA content were apoptotic using Annexin V/7-AAD staining kit (BD Bioscience). As shown in Fig. 2A, the predominant effect of Naph was observed in Quadrant 2 (Annexin $\mathrm{V}^{+} / 7-\mathrm{AAD}^{+}$, late apoptosis) or Quadrant 1 (Annexin $\mathrm{V}^{-} / 7-\mathrm{AAD}^{+}$, necrosis). Treatment with $0,0.7$ and $1.5 \mu \mathrm{M}$ of Naph for $24 \mathrm{~h}$ increased the late apoptotic cell numbers to $0,6.7 \pm 1.9$ and $16.7 \pm 3.69 \%$, respectively and the necrotic cells to $0,5.5 \pm 1.91,11.7 \pm 1.55 \%$, respectively. Early apoptotic cells (Quadrant 4, Annexin $\mathrm{V}^{+} /$7-AAD ${ }^{-}$) were $2.1 \%$ of total population in control, whereas treatment with Naph at 0.7 and $1.5 \mu \mathrm{M}$ increased apoptotic cell number to 
A

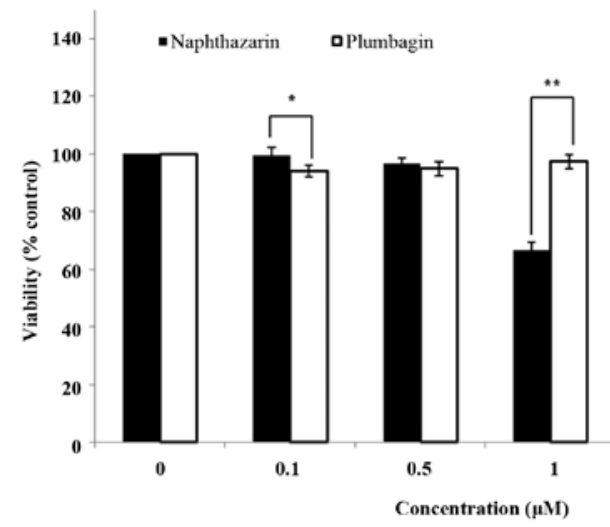

C
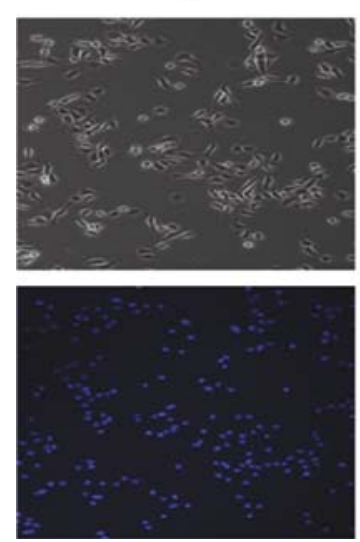

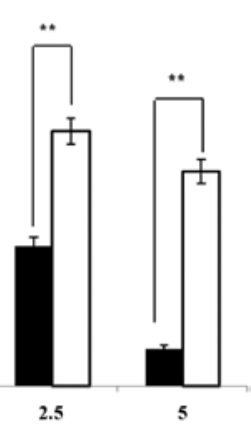

$0.7 \mu \mathrm{M}$
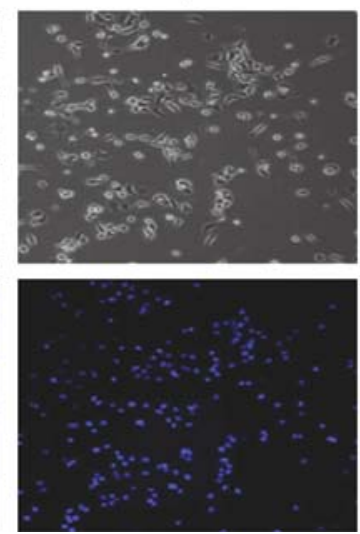

B

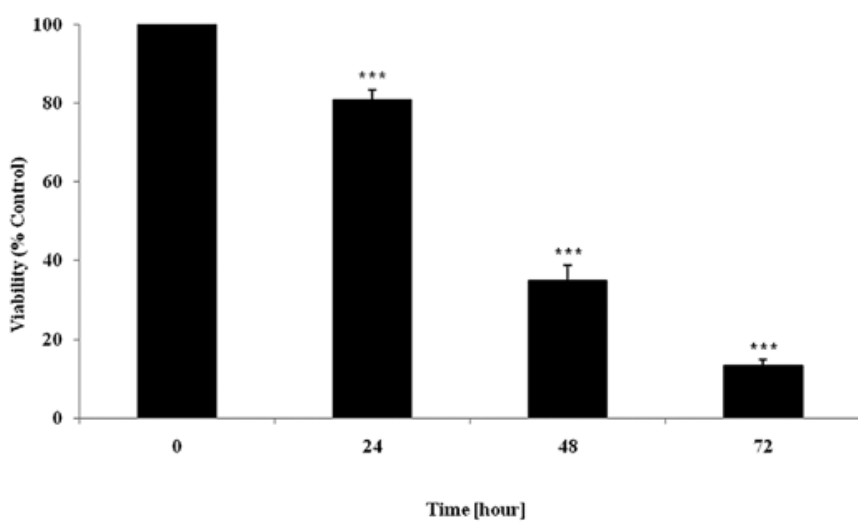

$1.5 \mu \mathrm{M}$
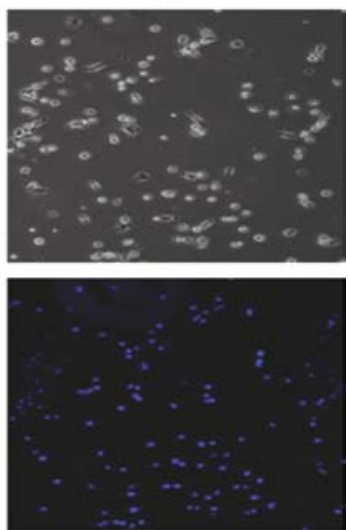

Figure 1. Effect of naphthazarin on cell viability and proliferation. (A) Comparative cell viability in the presence of plumbagin or naphthazarin and (B) inhibitory effect of naphthazarin on cell proliferation in AGS gastric cancer cells as measured by the MTS assay. (C) Cells were imaged and stained with DAPI. AGS cells were seeded in 6-well culture plates. After incubation for one day, the cells were treated with various concentrations of plumbagin or naphthazarin. After 24-h incubation, the cells were subjected to an MTS assay and imaged immediately thereafter. Results are expressed as a percentage of control and represent the means \pm SD of three independent experiments. ${ }^{*} \mathrm{P}<0.05,{ }^{* *} \mathrm{P}<0.01,{ }^{* * *} \mathrm{P}<0.001$ compared with vehicle.

A
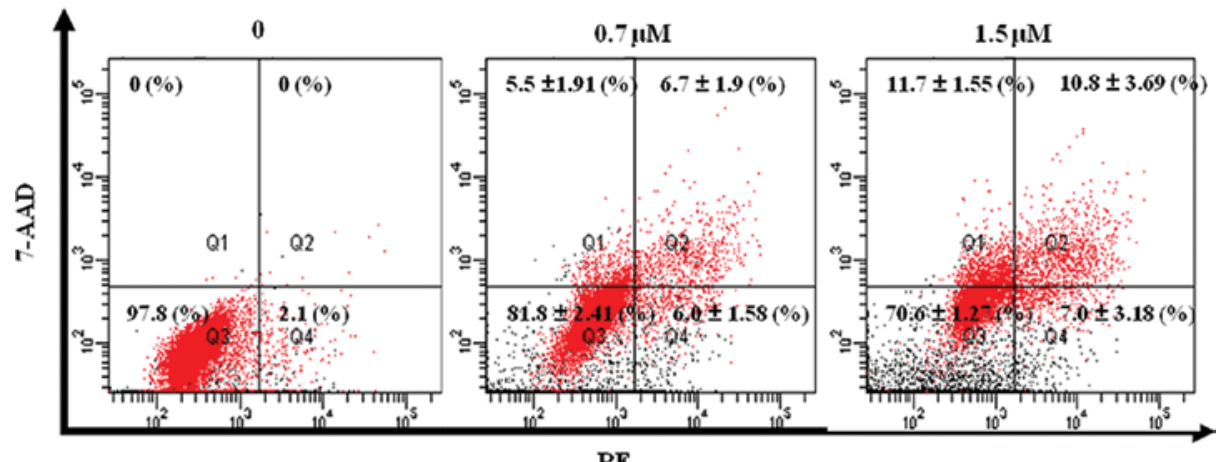

B

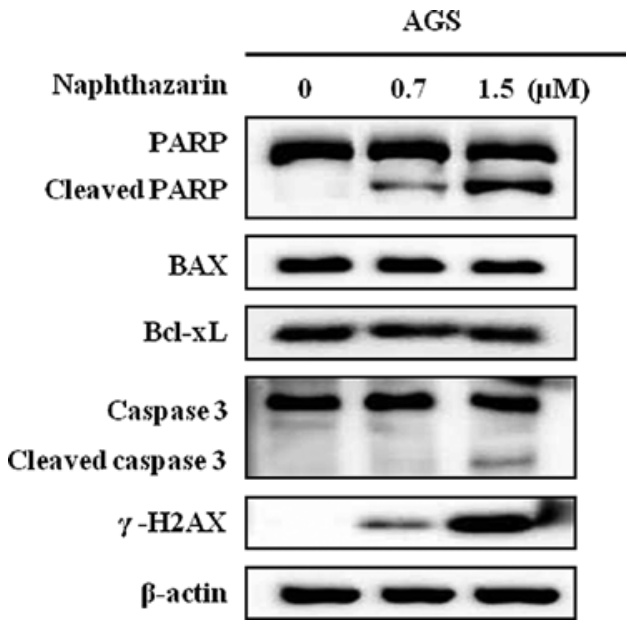

Figure 2. Effect of naphthazarin on apoptosis. (A) AGS cells were treated with naphthazarin $(0.7$ and $1.5 \mu \mathrm{M})$ for $24 \mathrm{~h}$, stained with PE annexin V and 7-amino-actinomycin (7-AAD) and analyzed on a FACS flow cytometer. (B) Expression of apoptosis-related genes by Western blot analysis. A representative immunoblot from three independent experiments is shown.

$6.0 \pm 1.58$ and $7.0 \pm 3.18 \%$, respectively. To confirm that Naph induced apoptosis, we also examined the expression levels of apoptosis-related proteins such as the cleavage of PARP and caspase- 3 as well as Bax, Bcl-xL and $\gamma-\mathrm{H} 2 \mathrm{AX}$ by Western blot analysis after Naph treatment for $24 \mathrm{~h}$ (Fig. 2B). As a result, Naph caused the activation of cleaved caspase-3 and subsequently the cleavage of PARP in AGS cells in 
A
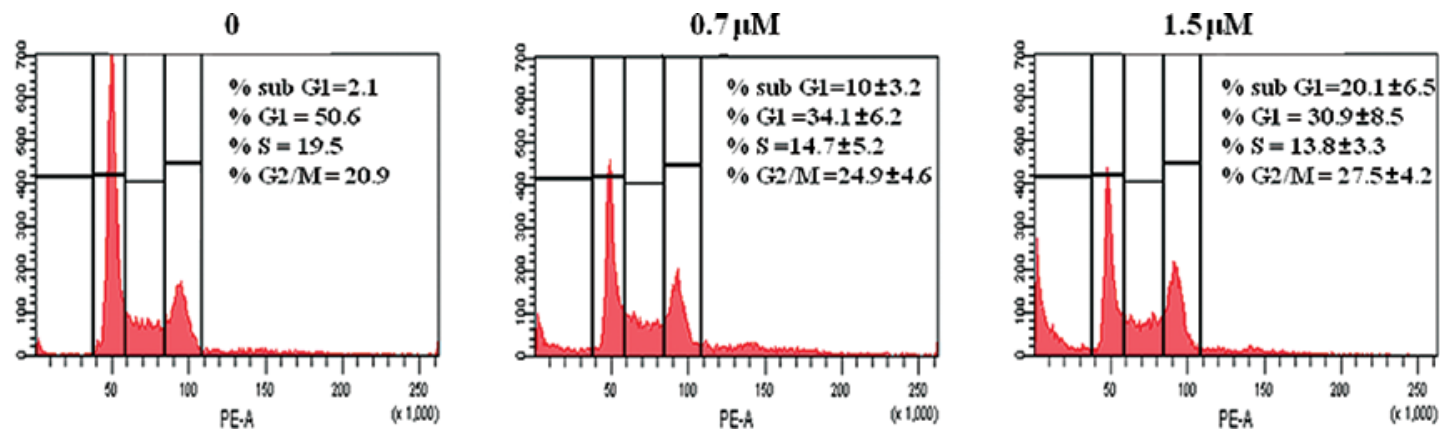

B

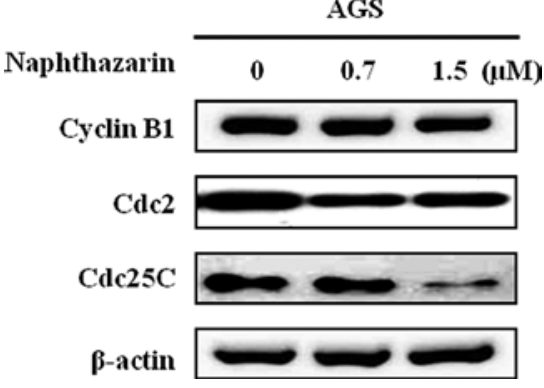

A

0
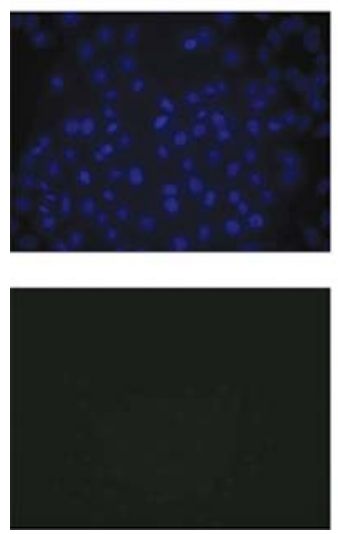

B
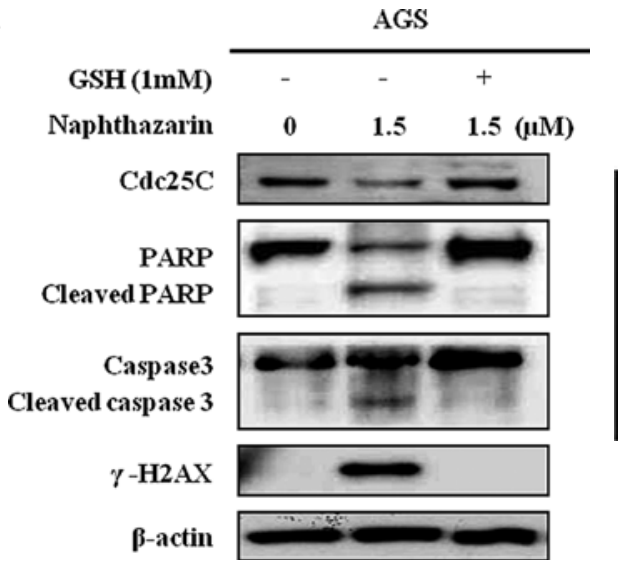

$0.7 \mu \mathrm{M}$
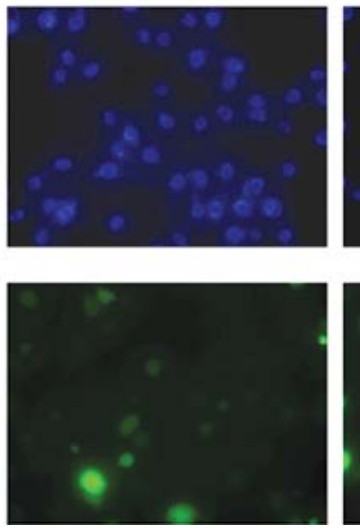

C
Figure 3. Effect of naphthazarin on cell cycle arrest. (A) AGS cells were treated with the indicated concentrations of naphtazarin for $24 \mathrm{~h}$, stained with propidium iodide (PI) and analyzed on a FACS flow cytometer. (B) G2/M phage cell cycle-related gene expression by Western blot analysis. A representative immunoblot from three independent experiments is shown.

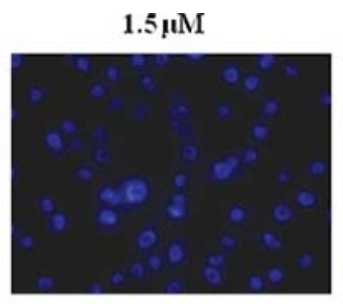

$\operatorname{GSH}(1 \mathrm{mM})+1.5 \mu \mathrm{M}$
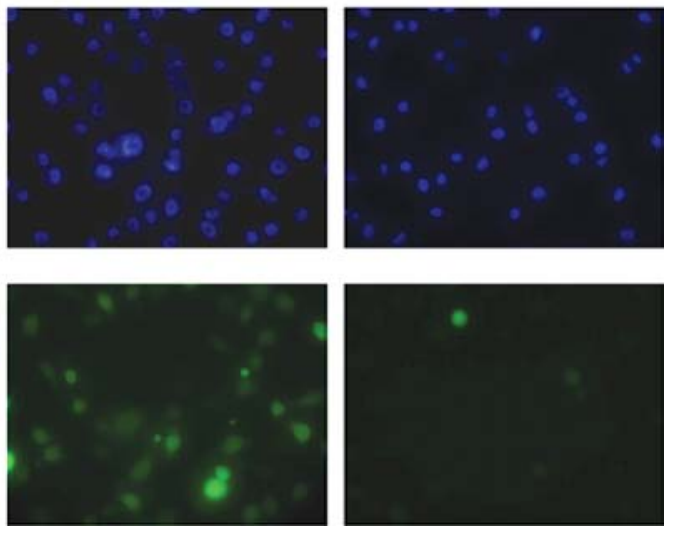
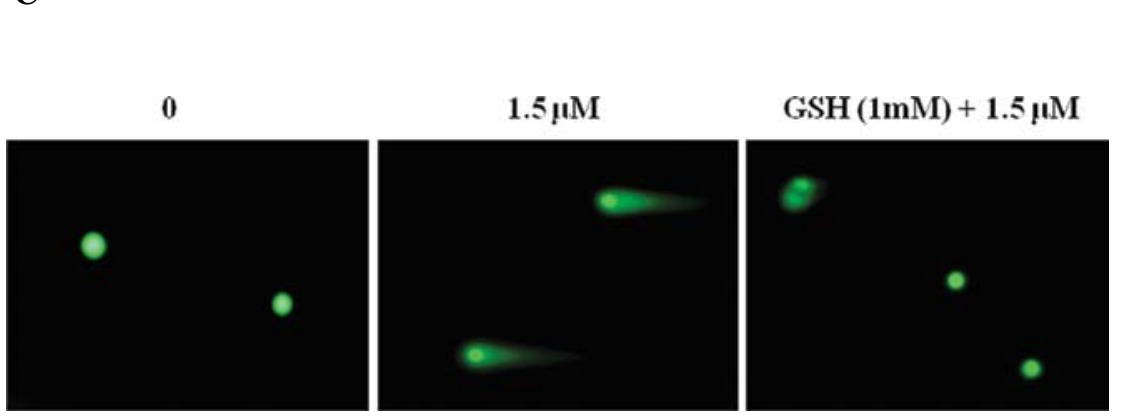

Figure 4. The role of ROS on naphthazarin-induced apoptosis and cell cycle arrest. Glutathione (GSH) attenuated naphthazarin-mediated ROS generation (A), apoptosis- or cell cycle arrest-related genes expression (B) and DNA fragmentation (C). Cells were pre-treated with GSH (1 mM) for $30 \mathrm{~min}$, and then $1.5 \mu \mathrm{M}$ of naphthazarin was added. One representative result is shown from three independent experiments that yielded similar results.

a dose-dependent manner. Expression of $\gamma$-H2AX, which promotes DNA repair and maintains genomic stability (15), was also induced by Naph, but the expression of Bax and Bcl-xL was not altered by Naph. These results indicated that Naph may induce apoptosis in AGS cells.
Effect of naphthazarin on cell cycle arrest in AGS cells. Cell proliferation and apoptosis are associated with cell cycle progression (16). Naph induced dose-dependent inhibition of cell growth and significant apoptosis at the indicated doses in AGS cells. These results implied that Naph may affect the cell cycle. 
As shown in Fig. 3A, changes of the cell cycle profile induced by Naph were analyzed using flow cytometer. Cells were harvested $24 \mathrm{~h}$ after Naph treatment $(0,0.7$ and $1.5 \mu \mathrm{M})$ and stained with propidium iodide (PI) for the distribution of sub-G1, G1, S and $\mathrm{G} 2 / \mathrm{M}$ phases of the cell cycle. Treatment with 0.7 and $1.5 \mu \mathrm{M}$ of Naph induced G2/M phage arrest and cell death determined by the Sub-G1 population. Cycline B1, Cdc2 and Cdc25C are related to cell cycle arrest $(17,18)$. Thus, we evaluated the effect of Naph on regulation of their protein expression. $\mathrm{G} 2 / \mathrm{M}$ phase arrest by Naph was accompanied by a decrease in $\mathrm{Cdc} 2$ and $\mathrm{Cdc} 25 \mathrm{C}$ in AGS cells (Fig. 3B), while cycline B1 was not changed. These results suggested that Naph may induce DNA damage, resulting in cell cycle arrest at $\mathrm{G} 2 / \mathrm{M}$ by decreasing $\mathrm{Cdc} 2$ and $\mathrm{Cdc} 25 \mathrm{C}$ expression in AGS cells.

GSH abolishes the effect of naphthazarin on apoptosis and cell cycle arrest in AGS cells. Oxidative stress causes cellular injury, which may induce cell cycle arrest and apoptosis (11). Thus, we investigated whether Naph induced ROS generation in the cells. AGS cells were treated Naph with at $0,0.7$ and $1.5 \mu \mathrm{M}$ for $30 \mathrm{~min}$ and ROS generation was measured using DCFDA dye. Fig. 4A shows that ROS generation was increased by Naph treatment, but that the generated ROS were abolished in the presence of GSH. In addition, we confirmed whether the effect of Naph on apoptosis and cell cycle arrest in AGS cells occurred in the presence of GSH. Cells were pretreated with GSH for $30 \mathrm{~min}$, subsequently exposed to Naph and then the expression of apoptosis-related proteins (cleaved PARP and caspase- 3 and $\gamma$-H2AX) and cell cycle related proteins (Cdc25C) was assessed (Fig. 4B). Cleaved PARP and caspase-3 and induced $\gamma-\mathrm{H} 2 \mathrm{AX}$ in AGS cells treated with Naph was abolished with GSH pretreatment. Further, the decreased Cdc $25 \mathrm{c}$ expression recovered to control levels. These results indicated that the cytotoxic effect of Naph may be caused by ROS.

\section{Discussion}

In this study, we have demonstrated the anti-cancer effect of Naph by inducing AGS cell apoptosis and inhibiting cell proliferation as well as investigated the mechanisms of these effects. We used 0.7 and $1.5 \mu \mathrm{M}$ of Naph as the effective doses because the $\mathrm{IC}_{50}$ of Naph was at $2.5 \mu \mathrm{M}$ and concentrations $<5 \mu \mathrm{M}$ was sub-lethal for 24-h treatment in AGS cells. Our results showed that Naph inhibited cancer cell viability and proliferation in AGS cells. DAPI staining, cell sorting and annexin V/7-AAD staining suggested that the predominant effect of Naph on gastric cancer cell viability may be due to induction of apoptosis in AGS cells. The increase in apoptosis-related gene expression by Naph was also confirmed in these cells. These findings indicated that Naph could effectively suppress AGS cell viability and proliferation. Moreover, it was clear that the anti-cancer effect of Naph is likely to be via induction of apoptosis and cell cycle arrest.

Apoptosis (programmed cell death) is the process of eukaryotic cell death, which is characterized by cell shrinkage, DNA fragmentation and apoptotic bodies (19). Our data also showed that Naph induced apoptosis by increasing DNA fragmentation, nuclear condensation, and cell morphological changes by DAPI staining. In the process of apoptosis, caspases have been reported to be activated via both the extrinsic and intrinsic cell death pathways $(20,21)$. In particular, the activation of caspase- 3 is commonly involved in the apoptosis process in various cell types. During apoptosis, caspase- 3 cleaves PARP, suppressing PARP activity $(22,23)$. In this study, we observed that Naph induced apoptosis of AGS cells by increasing expression of the cleaved caspase-3 and PARP, thereby implying that induction of apoptosis by Naph may be a contributing factor in the suppression of tumor growth.

The effect of candidate compounds on cell cycle arrest in cancer cells is another approach to test a candidate for its efficiency in cancer prevention and treatment. In this study, we observed that Naph significantly suppressed AGS cell proliferation in a time- and dose-dependent manner. Cyclin B1, $\mathrm{Cdc} 2$ and $\mathrm{Cdc} 25 \mathrm{C}$ have been shown to play an important role in cell cycle progression from $\mathrm{S}$ to $\mathrm{G} 2 / \mathrm{M}$ phases $(17,18)$. Our data showed that $\mathrm{Cdc} 2$ and $\mathrm{Cdc} 25 \mathrm{C}$ were down-regulated in a dose-dependent manner after Naph treatment and these alterations were consistent with induction of $\mathrm{G} 2 / \mathrm{M}$ arrest. Therefore, alterations of $\mathrm{Cdc} 2$ and $\mathrm{Cdc} 25 \mathrm{C}$ might be correlated with Naph-induced G2 arrest and finally lead to inhibition of cell proliferation in AGS cells.

The mechanisms underlying the cytotoxicity of naphthaquinone as electron transfer agents is accepted i.e., their reactive species generation and electrophilicity $(24,25)$. During redox cycling, naphthaquinone generates superoxide anion $\left(\mathrm{O}_{2}{ }^{\circ}\right)$ and hydrogen peroxide $\left(\mathrm{H}_{2} \mathrm{O}_{2}\right)$ by NADPH-cytochrome $\mathrm{P} 450$ reductase. The electrophilic naphthaquinone is capable of reacting with the thiol group of proteins and GSH (26). These two mechanisms may thereby have been associated with naphthaquinone-induced cytotoxicity and oxidative stress. Owing to their cytotoxicity, naphthaquinone and its derivatives have been investigated as model compounds for the development of anti-cancer drugs acting on target cells both by the generation of reactive metabolites and by directly interfering with cellular enzymes crucial for cell proliferation (3-5). We also found that the decreased cell viability and proliferation mediated by Naph correlated with ROS-dependent apoptosis induction. This conclusion is supported by our observations that Naph caused ROS generation in a dose-dependent manner and increased apoptosis-related gene expression. In addition, the cytotoxicity of Naph was significantly attenuated in the presence of GSH, suggesting oxidative stress as a possible mechanism for its effect.

In conclusion, our findings showed that Naph inhibited cell proliferation and induced apoptosis in parallel with increased oxidative stress. These findings lead us to believe that Naph may be a potential candidate as an anti-cancer drug. However, there are still further studies needed to investigate other mechanisms of action such as angiogenesis, invasion and migration.

\section{Acknowledgements}

This research was supported by National R\&D Program through the Dongnam Institute of Radiological \& Medical Sciences (DIRAMS) funded by the Ministry of Education, Science and Technology (50492-2011). The authors declare that there are no conflicts of interest.

\section{References}

1. Tsujimoto $\mathrm{H}$, Ono S, Ichikura T, et al: Roles of inflammatory cytokines in the progression of gastric cancer: friends or foes? Gastric Cancer 13: 212-221, 2010. 
2. Park JM, Xian XS, Choi MG, et al: Antiproliferative mechanism of a cannabinoid agonist by cell cycle arrest in human gastric cancer cells. J Cell Biochem 112: 1192-1205, 2011.

3. Ji YB, Qu ZY, Zou X, et al: Juglone-induced apoptosis in human gastric cancer SGC-7901 cells via the mitochondrial pathway. Exp Toxicol Pathol 63: 69-78, 2011.

4. Aithal BK, Kumar MR, Rao BN, et al: Juglone, a naphthoquinone from walnut, exerts cytotoxic and genotoxic effects against cultured melanoma tumor cells. Cell Biol Int 33: 1039-1049, 2009.

5. Sugie S, Okamoto K, Rahman KM, et al: Inhibitory effects of plumbagin and juglone on azoxymethane-induced intestinal carcinogenesis in rats. Cancer Lett 127: 177-183, 1998.

6. Shieh JM, Chiang TA, Chang WT, et al: Plumbagin inhibits TPA-induced MMP-2 and u-PA expressions by reducing binding activities of NF-kappaB and AP-1 via ERK signaling pathway in A549 human lung cancer cells. Mol Cell Biochem 335: 181-193, 2010.

7. Powolny AA and Singh SV: Plumbagin-induced apoptosis in human prostate cancer cells is associated with modulation of cellular redox status and generation of reactive oxygen species. Pharm Res 25: 2171-2180, 2008.

8. Kuo P, Hsu YL, Cho CY, et al: Plumbagin induces G2-M arrest and autophagy by inhibiting the AKT/mammalian target of rapamycin pathway in breast cancer cells. Mol Cancer Ther 5: 3209-3221, 2006.

9. Hsu YL, Cho CY, Kuo PL, et al: Plumbagin (5-hydroxy-2-methyl1,4-naphthoquinone) induces apoptosis and cell cycle arrest in A549 cells through p53 accumulation via c-Jun NH2-terminal kinase-mediated phosphorylation at serine 15 in vitro and in vivo. J Pharmacol Exp Ther 318: 484-494, 2006.

10. Gomathinayagam R, Sowmyalakshmi S, Mardhatillah F, et al: Anticancer mechanism of plumbagin, a natural compound, on non-small cell lung cancer cells. Anticancer Res 28: 785-792, 2008.

11. Ollinger K and Brunk UT: Cellular injury induced by oxidative stress is mediated through lysosomal damage. Free Radic Biol Med 19: 565-574, 1995

12. Song G.Y, Kim Y, You YJ, et al: Naphthazarin derivatives (VI): synthesis, inhibitory effect on DNA topoisomerase-I and antiproliferative activity of 2- or 6-(1-oxyiminoalkyl)-5,8-dimethoxy-1,4-naphthoquinones. Arch Pharm (Weinheim) 333: 87-92, 2000 .

13. Yong-Kee CJ, Salomonczyk D, Nash JE, et al: Development and validation of a screening assay for the evaluation of putative neuroprotective agents in the treatment of Parkinson's disease. Neurotox Res 19: 519-526, 2011.
14. Kang JJ, Lee PJ, Chen YJ, et al: Naphthazarin and methylnaphthazarin cause vascular dysfunction by impairment of endothelium-derived nitric oxide and increased superoxide anion generation. Toxicol In Vitro 20: 43-51, 2006.

15. Bourton EC, Plowman PN, Smith D, et al: Prolonged expression of the gamma-H2AX DNA repair biomarker correlates with excess acute and chronic toxicity from radiotherapy treatment. Int J Cancer (In press).

16. Hwang ES, Lee HJ, et al: Effects of phenylethyl isothiocyanate and its metabolite on cell-cycle arrest and apoptosis in LNCaP human prostate cancer cells. Int J Food Sci Nutr 61: 324-336, 2010.

17. Ou TT, Wang CJ, Lee YS, et al: Gallic acid induces G2/M phase cell cycle arrest via regulating 14-3-3beta release from Cdc25C and Chk2 activation in human bladder transitional carcinoma cells. Mol Nutr Food Res 54: 1781-1790, 2010.

18. Singh SV, Herman-Antosiewicz A, Singh AV, et al: Sulforaphaneinduced $\mathrm{G} 2 / \mathrm{M}$ phase cell cycle arrest involves checkpoint kinase 2 -mediated phosphorylation of cell division cycle $25 \mathrm{C}$. J Biol Chem 279: 25813-25822, 2004.

19. Spencer SL and Sorger PK: Measuring and modeling apoptosis in single cells. Cell 144: 926-939, 2011.

20. Fossati S, Cam J, Meyerson J, et al: Differential activation of mitochondrial apoptotic pathways by vasculotropic amyloid-beta variants in cells composing the cerebral vessel walls. FASEB J 24: 229-241, 2010.

21. Wang GQ, Gastman BR, Wieckowski E, et al: Apoptosis-resistant mitochondria in T cells selected for resistance to Fas signaling. J Biol Chem 276: 3610-3619, 2001.

22. Koh DW, Dawson TM and Dawson VL: Poly(ADP-ribosyl)ation regulation of life and death in the nervous system. Cell Mol Life Sci 62: 760-768, 2005.

23. Yu SW, Wang H, Dawson TM, et al: Poly(ADP-ribose) polymerase-1 and apoptosis inducing factor in neurotoxicity. Neurobiol Dis 14: 303-317, 2003.

24. Klaus V, Hartmann T, Gambini J, et al: 1,4-Naphthoquinones as inducers of oxidative damage and stress signaling in $\mathrm{HaCaT}$ human keratinocytes. Arch Biochem Biophys 496: 93-100, 2010.

25. Ollinger $\mathrm{K}$ and Brunmark A: Effect of hydroxy substituent position on 1,4-naphthoquinone toxicity to rat hepatocytes. J Biol Chem 266: 21496-21503, 1991.

26. Castro FA, Mariani D, Panek AD, et al: Cytotoxicity mechanism of two naphthoquinones (menadione and plumbagin) in Saccharomyces cerevisiae. PLoS One 3: e3999, 2008. 